\title{
Spinal metallosis as a complication of a lodged bullet from a firearm wound: an image-centered case
}

\author{
Isabela Machado ${ }^{1}$ \\ Daniel de Paula Garcia ${ }^{1}$ \\ Carolina Souza Tannus ${ }^{1}$ \\ Koji Tanaka ${ }^{2}$ \\ Fred Bernardes Filho ${ }^{3}$ \\ Mauro Jose Brandao da Costa ${ }^{1,4}$ \\ (iD) Rodolfo Mendes Queiroz ${ }^{1,4}$
}

\begin{abstract}
1. Department of Radiology and Imaging, DOCUMENTA, São Francisco Hospital, Ribeirão Preto, SP, Brasil 2. Division of Neurosurgery of the Department of Surgery and Anatomy, Hospital das Clínicas of the Faculty of Medicine of Ribeirão Preto of the University of São Paulo, Ribeirão Preto, SP, Brasil 3. Division of Dermatology of the Department of Clinical Medicine, Hospital das Clínicas of the Faculty of Medicine of Ribeirão Preto of the University of São Paulo, Ribeirão Preto, SP, Brasil 4. Department of Radiology and Imaging, SER IMAGEM, Santa Casa de Misericórdia de Sertãozinho Hospital, Sertãozinho, SP, Brasil
\end{abstract}

KEYWORDS: Wounds, gunshot. Spine. Spinal injuries. Stainless steel/adverse effects.

\section{INTRODUCTION}

A male patient, 43 years old, with strong lumbar pain, paresthesia of the lower limbs and progressive ambulation difficulty for four years, with complete disability in the last month. History of firearm wound in the lumbar spine 21 years ago. At the time, surgery was conducted to decompress the spinal canal in a distinct hospital unit at another location, without the use of cement or grafting, or the removal of the projectile. Normal general laboratory results.

In a computed tomography (CT) of the lumbar spine, it was found L2 and L3 laminectomy with a voluminous material with metallic density occupying part of the internal space of the spinal canal and intervertebral foramen (figures $1 \mathrm{~A}, 1 \mathrm{~B}, 1 \mathrm{C}$, and 1D) In the magnetic resonance imaging (MRI), the same material was characterized with hypointense signal on all sequences, including T1-weighted (Figure 2A), T2-weighted (Figure 2B), and Stir (Figure 2C), with a slight highlight of surrounding tissues in $\mathrm{T} 1$ after the administration of intravenous contrast medium (Figure 2D), in addition to strong compression effect on the conus medullaris.

The exams performed for determining the levels of serum and urinary lead presented normal values.

Surgery was performed to remove the material (Figure 3A). Which showed not only the fragmented projectile but also a great amount of locoregional tissue impregnated by metal residue.

The patient showed improvement of signs and symptoms after surgery. The fact that symptoms were compatible with spinal cord compression that progressively evolved over the years, with no associ- 


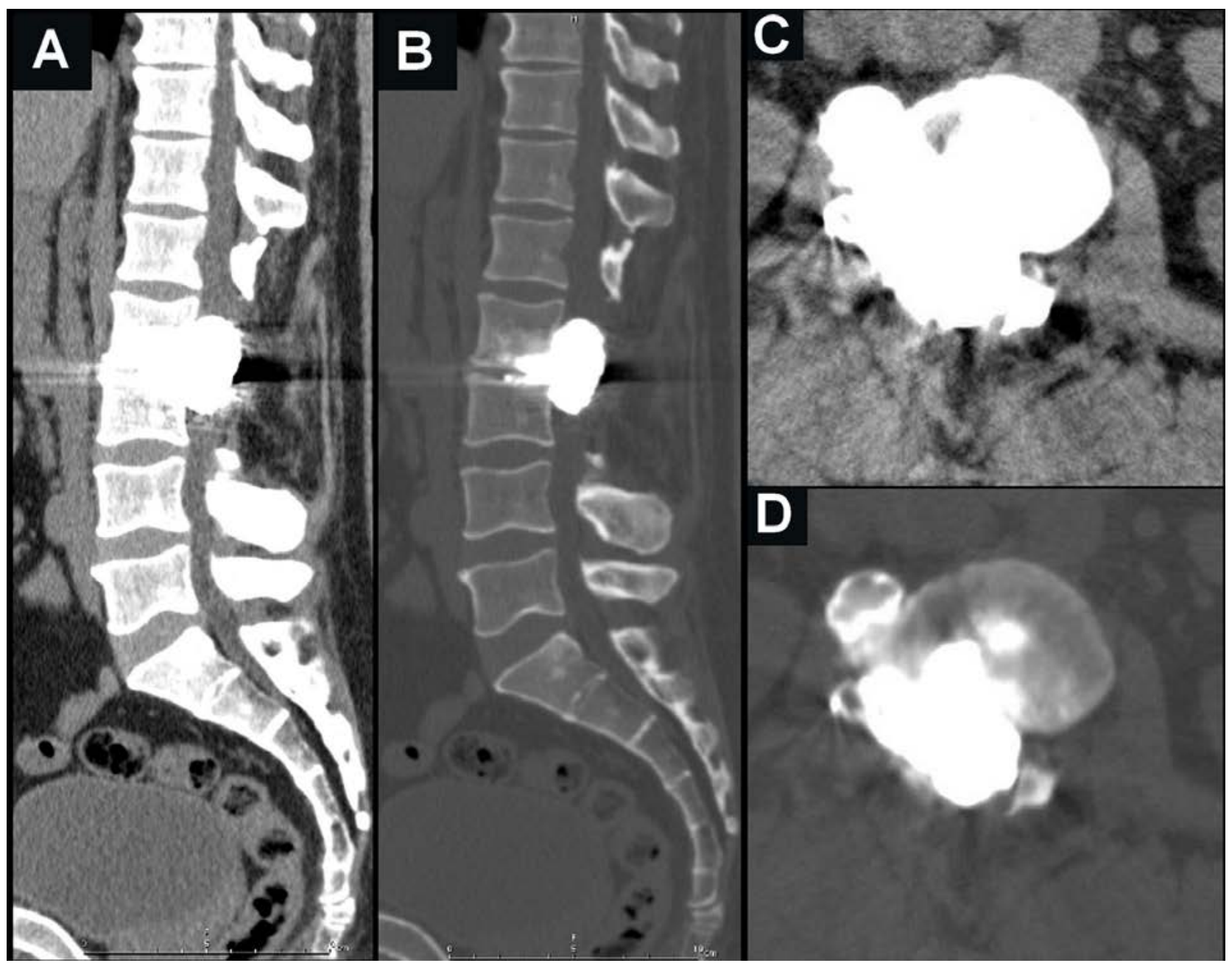

FIGURE 1. $C T$ of the lumbar spine $(A, B, C, D)$ characterizing a large irregular material with metal density occupying most of the spinal canal and disc space at L2-L3.

ated central neurological or systemic symptoms, in addition to the metal impregnated tissued removed being bigger than the projectile, explains the gradually increasing effect and the findings as a whole suggest a metallosis diagnosis.

\section{DISCUSSION}

With the increase in crime rates, the number of patients with firearm wounds in the spinal column has also increased. It is estimated that this is responsible for $17 \%$ of spine trauma cases, surpassed only by car accidents, which are still the main cause of such lesions.

Lead poisoning due to firearm wounds is unusual and can occur in individuals with bullets lodged for a short period of time, but there are also reported cases of trauma that happened over 50 years. The location of the projectile is the main risk factor. When the bullet is located inside of the joints, a fibrous bar- rier is formed, but the constant contact with fluids may release lead particles that are absorbed by the bloodstream ${ }^{2}$.

The nervous system is the most sensitive to high levels of lead. The patient presents peripheral neuropathy associated with paresthesias, parkinsonism, and ataxia. Furthermore, extraneurologic symptoms can be found, such as weakness, abdominal pain, arthralgia, and anorexia ${ }^{3}$. Blood levels are considered elevated when above $25 \mathrm{ug} / \mathrm{dL}$ in children and $40 \mathrm{ug} /$ dL in adults ${ }^{3}$.

Metallosis is another complication that can occur in cases of chronic exposure to lead and other metals. It is mostly reported is cases of metallic implants or internal fixation of fractures, rarely in the spinal cord, with less than 50 cases reported ${ }^{4,5}$. It is a disease caused by microparticles resulting from an inflammatory process which form a metalloma. It begins with the building up of interstitial fluid around the projectile and micromovements that wear the metal. Then 


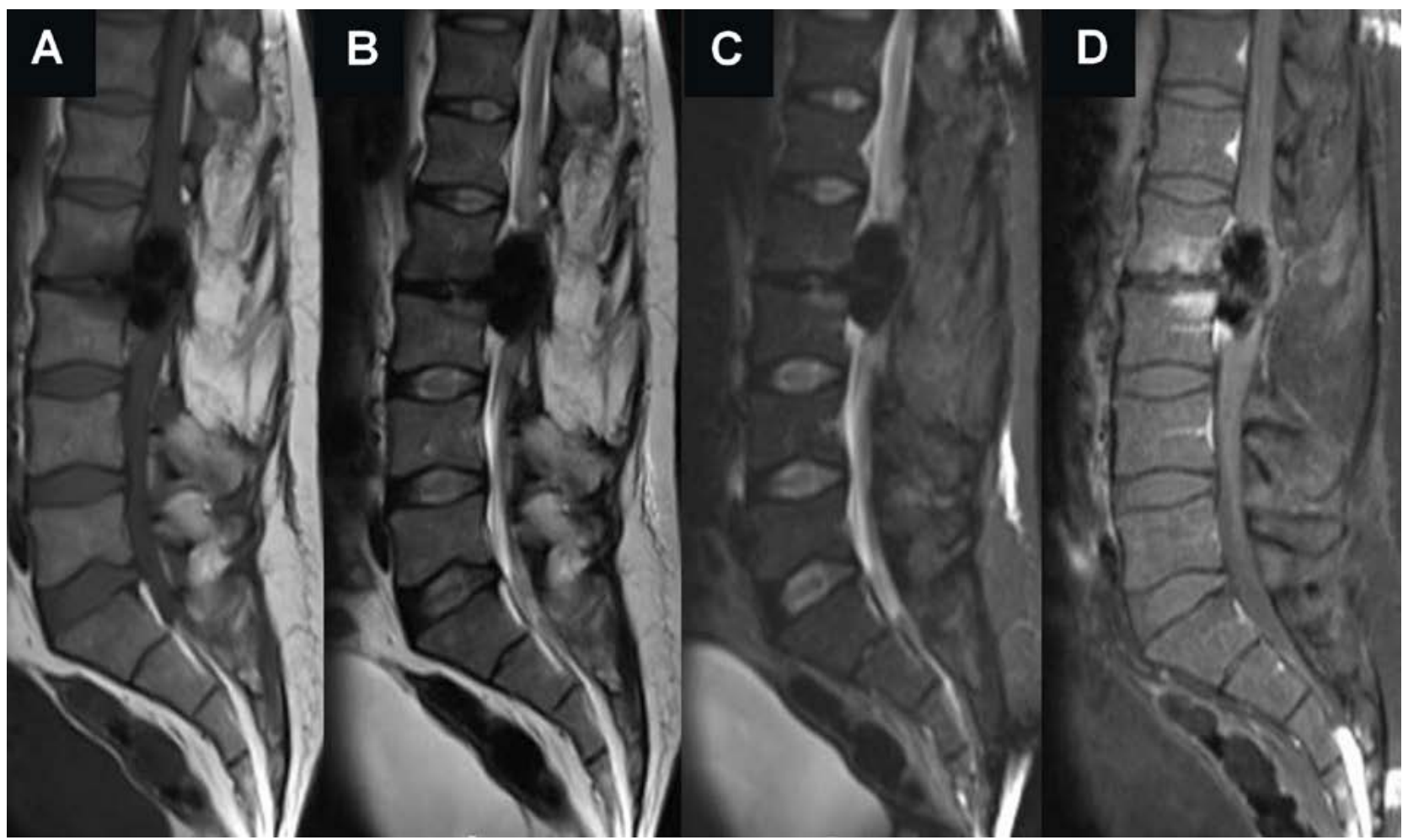

FIGURE 2. MRI of the lumbar spine showing a material characterized with a hypointense signal on all weighted sequences at T1 (A), T2 (B), and STIR (C), with a slight highlight of surrounding tissues in T1 after the administration of intravenous contrast medium, in addition to a strong compression effect on the conus medullaris.

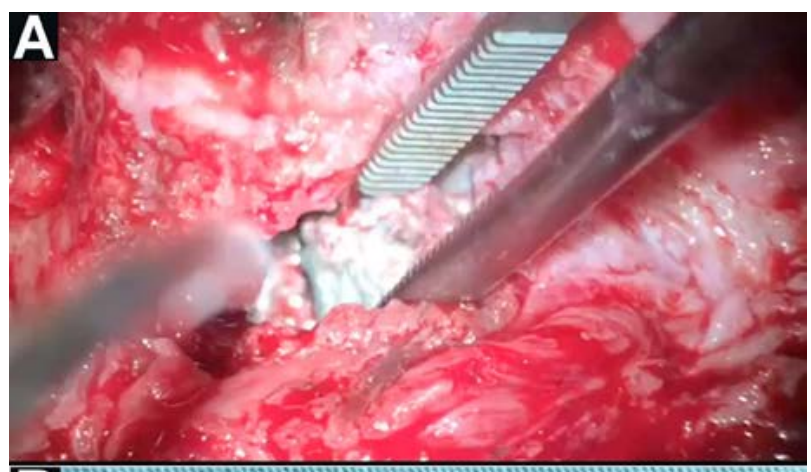

B

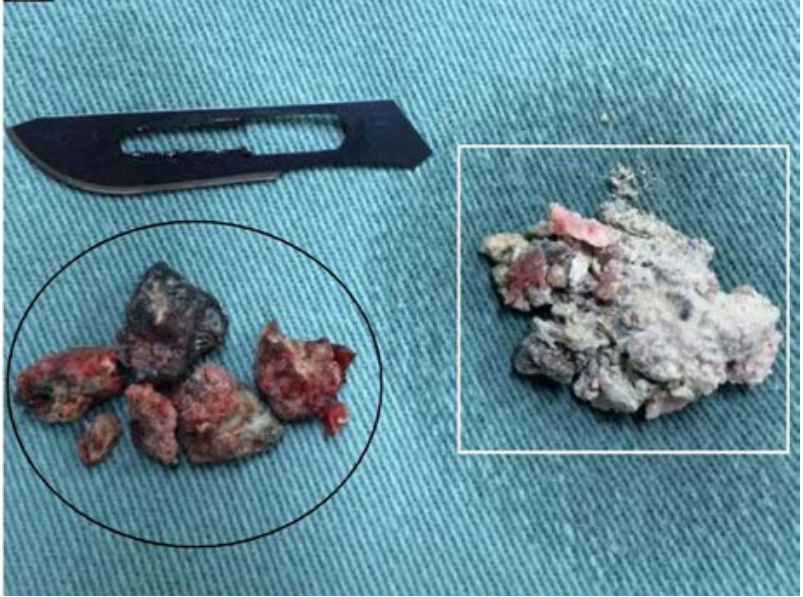

an inflammatory reaction occurs, with the migration of macrophages. The phagocytosis accentuates the inflammatory process with bone resorption and granuloma formation. If that process is not interrupted, the granuloma results in a metalloma ${ }^{5}$.

The imaging exam of choice is the CT myelogram. Artifacts may occur in CT scans and MRIs due to the presence of metallic material, which makes the assessment more difficult ${ }^{5,6}$. The CT highlights bone erosion, spinal instability, and spinal canal impairment. MRIs can be contraindicated depending on the composition and location of the bullet, and it is not recommended in acute cases or in cases of incomplete spinal cord injuries ${ }^{5,7}$.

There is no consensus regarding the surgical approach, especially when there is no clear evidence of corrosion, and it is mostly used in critical situations ${ }^{1-5,8}$. According to data analyzed by Azevedo-Filho, in some patients that underwent decompressive laminectomy, a higher mortality rate was found, and some specific complications were more frequent, such as spinal cord injuries, fistulas, meningitis, and locoregional post-surgery infections.

FIGURE 3. Exeresis of the material described in the lumbar spine (A), evidencing, in a macroscopic visual analysis, (B) the fragmented projectile (black circle) and an accentuated amount of tissue impregnated with metal residues (white rectangle), which characterizes a metalloma. 
PALAVRAS-CHAVE: Ferimentos por arma de fogo. Coluna vertebral. Traumatismos da coluna vertebral. Aço inoxidável/efeitos adversos.

\section{REFERENCES}

1. Pimentel MG, Gomes EGF, Gusmão MS, Amorim Junior DC, Simões MTV, Gomes JF, et al. Epidemiological study of trauma of spinal cord trauma by a projectile of firearm in the hospital geral do Estado da Bahia. Coluna/Columna. 2012;11(4):298-301.

2. Cristante AF, Souza FI, Barros Filho TE, Oliveira RP, Marcon RM. Lead poisoning by intradiscal firearm bullet: a case report. Spine (Phila Pa 1976). 2010;35(4):E140-3.

3. Bustamante ND, Macias-Konstantopoulos WL. Retained lumbar bullet: a case report of chronic lead toxicity and review of the literature. J Emerg Med. 2016;51(1):45-9.

4. Oliveira CA, Candelária IS, Oliveira PB, Figueiredo A, Caseiro-Alves F. Metallosis: a diagnosis not only in patients with metal-on-metal prostheses. Eur J Radiol Open. 2014;2:3-6.
5. Goldenberg Y, Tee JW, Salinas-La Rosa CM, Murphy M. Spinal metallosis: a systematic review. Eur Spine J. 2016;25(5):1467-73.

6. Marconato JA, Aesse FF, Ferreira JHP, Pinheiro CP, Mazzola AA. Lumbar spine computed tomography after arthrodesis with metal implant: a qualitative evaluation of images reconstructed with different mathematical algorithms. Radiol Bras. 2007;40(1):17-22.

7. Rentfrow $B$, Vaidya R, Elia C, Sethi A. Lead toxicity and management of gunshot wounds in the lumbar spine. Eur Spine J. 2013;22(11):2353-7.

8. Barros Filho TE, Cristante AF, Marcon RM, Ono A, Bilhar R. Gunshot injuries in the spine. Spinal Cord. 2014;52(7):504-10.

9. Azevedo-Filho HRC. Gunshot wounds to the spine: study of 246 patients. Arq Neuro-Psiquiatr. 2001;59(3A):645-6. 